Institute of $\mathbf{F}_{\text {ood and }} \mathbf{A}$ gricultural $\mathbf{S}_{\text {ciences }}$

\title{
Florida Fresh: Cabbage ${ }^{1}$
}

Jennifer Hillan ${ }^{2}$

You can buy delicious fruits and vegetables at farmers' markets. You can also ask the person who grew it how to eat it! Because the produce is locally grown, it's fresh and costs less than at the supermarket. Enjoy some of your favorites or try something new! To find a farmers' market in your area, call your county Extension office or visit the Florida Department of Agriculture's web site: www.fl-ag.com/farmmkt/city.htm.

\section{History and Facts}

Ancient Greeks and Romans

believed cabbage could cure almost any illness.

Cabbage, broccoli, and Brussels sprouts are cruciferous vegetables. They have chemical compounds that may help prevent certain types of cancer.

Adding vinegar or a piece of bread to cabbage while it's cooking may reduce the odor.

One cup of chopped, raw cabbage gives us about onethird $(30 \%)$ of the vitamin C we need each day!

\section{Availability}

November through June

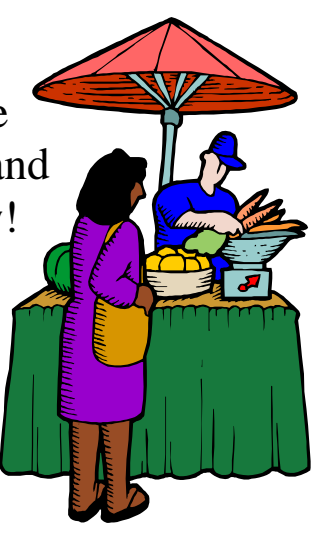

\section{Selection}

Choose cabbage that is even-colored and heavy for its size, with fresh, crisp leaves. Avoid discolored, wilted, or blemished cabbage.

\section{Storage}

Loosely cover unwashed, uncut cabbage in plastic wrap. Store in the refrigerator crisper for one to two weeks. Cut cabbage should be tightly covered and used within two days.

\section{Uses \& Preparation}

Rinse cabbage and remove outer leaves before using. Raw and cooked cabbage is popular in many dishes, including soups, coleslaw, and corned beef and cabbage.

To keep the most nutrients and reduce the odor, microwave, steam, or stir fry cabbage until it's just tender.

1. This document is FCS8676, one of a series of the Department of Family, Youth and Community Sciences, Florida Cooperative Extension Service, Institute of Food and Agricultural Sciences, University of Florida. Publication date: July 2002. Reviewed by Isabel Valentín-Oquendo, MS, RD, LD/N. Please visit the EDIS Web site at http://edis.ifas.ufl.edu

2. Jennifer Hillan, MSH, RD, LD/N, Coordinator, Educational/Training Programs, Department of Family, Youth and Community Sciences, Cooperative Extension Service, Institute of Food and Agricultural Sciences, University of Florida, Gainesville, 32611. 


\section{Nutrient Facts}

* Excellent source of vitamin C

* Good source of folate and fiber

* Fat and cholesterol free

\section{What are Organically Grown Foods?}

Organically grown means that a food was grown without synthetic (man-made) pesticides or fertilizers. Natural pesticides and fertilizers were used instead. Organic and non-organic foods are similar in taste and nutritional value. However, organic foods usually cost more.

\section{Super Coleslaw}

Serves 4

$1 / 2$ head cabbage, rinsed and shredded 1 large carrot, rinsed and shredded 2 small apples, rinsed and chopped $1 / 2$ cup raisins

2 tablespoons fat free yogurt

2 tablespoons lowfat mayonnaise dash vinegar

Combine all ingredients in large bowl and chill before serving.

Source: Produce for Better Health Foundation/Polyps Prevention Trial

\section{Oriental Cabbage Salad}

\section{Serves 6}

1 head cabbage, rinsed and shredded

1 tomato, rinsed and chopped

1 bunch green onions, rinsed and chopped

1 (12 oz.) can whole kernel sweet corn, drained

1 (3 oz.) package ramen noodles, crushed

$1 / 2$ cup sunflower seeds or chopped peanuts

$1 / 3$ cup vegetable oil

3 tablespoons sugar

3 tablespoons white vinegar

Add first six ingredients to large bowl. In small bowl, mix oil, sugar, vinegar, and noodle flavoring packet. Pour dressing over salad, toss, and serve immediately.

\section{Chicken Stir Fry}

Serves 4

2 chicken breasts, skin and bones removed, cut into small pieces

1 teaspoon vegetable oil

1 head cabbage, rinsed and torn into small pieces

1 small onion, chopped

1 tablespoon cornstarch

2 tablespoons fresh ginger, grated

2 cloves garlic, minced

$1 / 2$ cup water

1 tablespoon soy sauce

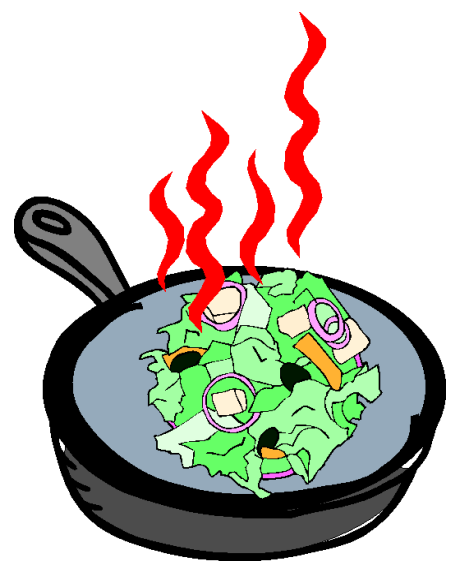

2 cups rice, cooked according to package directions

Heat oil and chicken in frypan over medium heat. Turn chicken constantly, and cook until chicken is no longer pink inside. Add cabbage and onions; stir-fry until cabbage is tendercrisp (about 2 minutes). Mix remaining ingredients (except rice) in small bowl; then add to chicken mixture. Cook and stir until liquid is thickened (about 1 minute). Serve over rice. 